\title{
A comprehensive DNA panel next generation sequencing approach supporting diagnostics and therapy prediction in neurooncology
}

Julia Lorenz ${ }^{1,2}$, Tanja Rothhammer-Hampl 1,2, Saida Zoubaa 1,2, Elisabeth Bumes ${ }^{2,3}$, Tobias Pukrop ${ }^{4}$, Oliver Kölbl2,5, Selim Corbacioglu ${ }^{6}$, Nils O. Schmidtt, ${ }^{2,}$, Martin Proescholdtt, ${ }^{2,}$, Peter Hau ${ }^{2,3}$ and Markus J. Riemenschneider ${ }^{1,2^{*}}$

\begin{abstract}
Recent updates in the classification of central nervous system (CNS) tumors have increased the need for molecular testing. Assessment of multiple alterations in parallel, complex combinations of gene sequence and chromosomal changes, as well as therapy prediction by identification of actionable mutations are the major challenges. We here report on a customized next generation sequencing (NGS)-based DNA panel assay that combines diagnostic and predictive testing and -as a comprehensive approach- allows for simultaneous single nucleotide variant (SNP) / small insertion/deletion (InDel), copy number variation (CNV) and loss of heterozygosity (LOH) detection. We analyzed formalin-fixed and paraffin-embedded (FFPE) DNA from a total of 104 patients with CNS tumors. After amplicon capture-based library preparation, sequencing was performed on the relatively cost-efficient Illiumina MiniSeq platform and evaluated with freely available bioinformatical tools. 57 genes for exonic SNP/InDel calling (19 of those in intronic regions for CNV analysis), 3 chromosomal arms and 4 entire chromosomes for CNV and LOH analysis were covered. Results were extensively validated. Our approach yielded high accuracy, sensitivity and specificity. It led to refined diagnoses in a relevant number of analyzed cases, reliably enabled complex subclassifications (e.g. for medulloblastomas) and identified actionable targets for clinical use. Thus, our singleplatform approach is an efficient and powerful tool to comprehensively support molecular testing in neurooncology. Future functionality is guaranteed as novel upcoming biomarkers can be easily incorporated in a modular panel design.
\end{abstract}

Keywords: Glioblastoma, Glioma, Meningioma, Medulloblastoma, Next generation sequencing, Targeted therapy, Integrated diagnoses

\footnotetext{
* Correspondence: markus.riemenschneider@ukr.de

'Department of Neuropathology, Regensburg University Hospital,

Franz-Josef-Strauss-Allee 11, 93053 Regensburg, Germany

${ }^{2}$ Wilhelm Sander Neuro-Oncology Unit, Regensburg University Hospital,

Regensburg, Germany

Full list of author information is available at the end of the article
}

C C The Author(s). 2020 Open Access This article is licensed under a Creative Commons Attribution 4.0 International License, which permits use, sharing, adaptation, distribution and reproduction in any medium or format, as long as you give appropriate credit to the original author(s) and the source, provide a link to the Creative Commons licence, and indicate if changes were made. The images or other third party material in this article are included in the article's Creative Commons licence, unless indicated otherwise in a credit line to the material. If material is not included in the article's Creative Commons licence and your intended use is not permitted by statutory regulation or exceeds the permitted use, you will need to obtain permission directly from the copyright holder. To view a copy of this licence, visit http://creativecommons.org/licenses/by/4.0/. The Creative Commons Public Domain Dedication waiver (http://creativecommons.org/publicdomain/zero/1.0/) applies to the data made available in this article, unless otherwise stated in a credit line to the data. 


\section{Introduction}

Diagnostic neurooncology has to deal with an increasing number of molecular markers for classification and therapy prediction. With the 2016 WHO classification of central nervous system (CNS) tumors, testing for molecular alterations is mandatory for some entities [1]. For example, the $I D H$ mutational status and codeletion of the chromosomal arms $1 \mathrm{p} / 19 \mathrm{q}$ need to be determined for the integrated diagnosis of an oligodendroglioma, $I D H$-mutant and $1 \mathrm{p} / 19 \mathrm{q}$-codeleted. This has to be regarded as a continuous development as beyond the current classification several additional markers are being proposed that will likely be integrated in upcoming revisions of the classification. The cIMPACT-NOW consortium, e.g., recently discussed the provisional entity of $I D H$-wildtype astrocytomas in terms of their heterogeneous outcomes. They recommended TERT promotor (TERTp) mutation, EGFR highcopy amplification and/or combined chromosome 7 gain and 10 loss as a marker to identify tumors with glioblastoma-like outcome on a molecular scale [2]. Also, for the group of IDH-mutant astrocytomas a reworked grading system was proposed, acknowledging homozygous loss of $C D K N 2 A$ as a main factor of unfavorable prognosis [3].

WHO grading and classification of meningiomas is still mainly based on histological characteristics [1]. Tumor behavior and risk of recurrence for each individual patient is often difficult to predict, even when main risk factors like patients' age, tumor size and extent of resection, as expressed by the Simpson grade scale, are considered [4, 5]. Several recent publications try to mitigate this uncertainty by defining molecular biomarkers or subgroups of tumors with a more favorable prognosis, reviewed in 2019 from the International Consortium on Meningiomas [5]. Beside the methylation-based subgrouping approach [6], there are several prognostic molecular biomarkers that appear meaningful in meningiomas. Unfavorable variations are CDKN2A loss, 1p loss and TERTp mutations [1, 6], while TRAF7, KLF4, AKT1 and SMO mutations are associated with a rather favorable prognosis [7]. It has been further described for meningioma that an increase in the complexity of copy number variations $(\mathrm{CNV})$ is correlated with a higher WHO grade $[4,5]$.

For medulloblastoma there is a more far-reaching consensus on molecular subgrouping. Since 2012 medulloblastoma can be divided into 4 different subgroups based on transcriptomics [8]. In the 2016 WHO classification the subgrouping proposal of the initial publication was partly considered and the following 4 subgroups were defined: WNT-activated, SHH-activated/TP53wildtype, SHH-activated/TP53-mutant and non-WNT/ non-SHH-activated [1]. Each of the 4 subgroups shows specific variations [9]. In the following, also immunohistochemistry-based approaches have been suggested to identify the 4 subgroups by using a set of 5 antibodies [10].

Covering this increasing amount of molecular markers with single gene assay approaches is often not expedient. Particularly in case multiple alterations on the gene and cytogenetic level have to be assessed in parallel, like e.g. for medulloblastomas, the application of highthroughput approaches appears indispensable. Combinations of i) methylation arrays for aspects connected to tumor classification $[6,11,12]$ and ii) targeted next generation sequencing (NGS) for the identification of actionable mutations [13] are a suitable approach to address this problem. However, high initial investment and annual costs for running two platforms in parallel hinder a fast expansion of the new techniques in the breadth of neuropathology. As a possible alternative, we aimed to develop a comprehensive NGS-based approach that should meet the following prerequisites: 1.) Coverage of all diagnostically relevant molecular alterations in astrocytic and oligodendroglial tumors, meningiomas and medulloblastomas for integrated diagnoses according to the 2016 WHO classification and beyond, 2.) cross-entity coverage of actionable mutations and alterations associated with therapy resistance. In order to fulfil these requirements the panel had to be designed in a way to reliably enable single nucleotide variant (SNP) and small insertion/deletion (InDel) calling as well as $\mathrm{CNV}$ and loss of heterozygosity (LOH) analysis. For LOH analyzes and to filter somatic aberrations from germline variations a matching blood sample had to be requested form each patient. The workflow had to be suitable for the framework of a quality-controlled diagnostic lab, i.e. in-house sequencing facility with optimal cost efficiency and timely turnaround time as well as suitability for formaldehyde-fixed and paraffin-embedded (FFPE) archival tissue samples.

\section{Materials and methods}

\section{Tissue samples}

In total, FFPE tissues from 104 patients with CNS tumors were analyzed. Samples were collected from the Neuropathology Department of Regensburg University Hospital (Regensburg, Germany) in line with local ethics board approval. All tumors were classified according the WHO 2016 diagnostic criteria [1]. In detail, 19 astrocytic gliomas, IDH-mutant (WHO grade II/III/IV); 14 oligodendrogliomas, IDH-mutant and $1 \mathrm{p} / 19 \mathrm{q}$-codeleted (WHO grade II/III); 42 astrocytic gliomas, $I D H$-wildtype, including 6 pilocytic astrocytomas (WHO grade I), 28 glioblastomas and 1 gliosarcoma (WHO grade IV); 2 diffuse midline gliomas, $H 3 K 27 M$-mutant (WHO grade 
IV); 8 medulloblastomas (WHO grade IV) and 19 meningiomas (WHO grade I/II/III) were analyzed.

\section{DNA extraction, library preparation and sequencing}

We designed a DNA panel that is suited for detection of DNA mutations, InDels, $\mathrm{LOH}$ and $\mathrm{CNV}$ (target region size: $459 \mathrm{kbp}$, total target bases analyzable: $254 \mathrm{kbp} ; 57$ genes, 4082 SNPs, $98.83 \%$ coverage). Genes and chromosomal regions included in the panel are listed in Suppl. Table 1. Most genes were covered using the complete coding sequence (CDS), for some genes with wellknown mutations only hotspot regions were covered. Chromosomal regions were covered with commonly heterozygous SNPs. 19 genes relevant for CNV analysis were additionally covered with commonly heterozygous SNPs in intronic regions. Genes and chromosomal regions were selected in a way to be 1) typical for a specific tumor entity (diagnostic), 2) indicate response to targeted therapies in other solid cancers (targetable) and/or 3) indicate drug resistance (resistance) [14, 15]. Additionally genes involved in DNA damage response (DDR) that point to the presence of a potential hypermutator phenotype were included.

Considerations on panel size, cost-efficiency, customizability, removal of PCR duplicates and the type of starting material (FFPE) led to the use of an amplicon capture-based target enrichment system (HaloPlex HS, Agilent) and the MiniSeq instrument (Illumina). The workflow is shown in Suppl. Figure 1. Total genomic DNA was isolated from FFPE tissue slides, using the GeneRead DNA FFPE Kit (Qiagen). Microdissection was administered prior to DNA extraction to increase tumor cell content where necessary. DNA was qualityassessed with an automated electrophoresis tool (Tapestation 4200, Agilent) and quantified using Quant-iT PicoGreen dsDNA Kit (Thermo Fisher Scientific) with the minimum requirements of $50 \mathrm{ng}$ to $200 \mathrm{ng}$ total mass for library preparation. Library preparation was performed with an amplicon capturebased target enrichment system according to manufacturer's guidelines (HaloPlexHS, Agilent). In short, DNA was digested with defined restriction enzymes and denatured. Target specific probe libraries including sequencing binding motives, indices, PCR oligonucleotides and molecular barcodes (for removal of PCR duplicates) were hybridized overnight to DNA targets. Uniquely barcoded targets were ligated and captured via streptavidin biotin binding. Enriched targets were amplified via PCR. Library quality and quantity was assessed using a TapeStation measurement (Agilent). Libraries were pooled and sequenced on a MiniSeq instrument (Illumina) with a theoretical average coverage of 750 -fold. Flow cells were selected according to sample number, required target coverage and required read length (300 bp paired end). The sequencing run was performed in the standalone modus resulting in raw bcl files.

\section{Data analysis}

NGS data analysis was performed with freely available, customizable tools on a Linux-based workstation. Bcl files were demultipexed (samples were separated according to indices) and converted into the fastq format with the bcl2fastq tool from Illumina, Version 1.8.4 [16]. Adaptor trimming was performed with the cutadapt tool [17] and quality checks in the standard fastq.gz format were performed with fastQC [18]. Resulting fastq files were aligned to the reference genome (GRch37) using the BWA mem tool [19] and further processed (sorted and indexed) with SAMtools 1.2 [20]. From the generated BAM-files, PCR duplicates were removed with the LocatIT tool [21]. To quantify NGS quality, percentages of target regions that were covered with a defined number of reads $(1,5,10,20,30,50,100,500$ and 1000 reads), the deduplication rate and read number in the deduplicated BAM file were considered. Data were then ready for further processing.

For SNP/InDel calling and CNV analysis the VarScan tool (v2.4.3) [22] and SAMtools mpileup (Version 1.2) were used [20]. The VarScan 2 algorithm reads SAMtools mpileup output from tumor and normal (in our case matched blood) samples simultaneously, performing pairwise comparisons of base calls and normalized sequence depth at each position. For variant detection, VarScan somatic determines the genotype for normal and tumor samples independently based on adjustable minimum thresholds for coverage, base quality, variant frequency and statistical significance. To refine SNP calling, the VarScan fpfilter was used as a false-positive filter that removes likely false positives due to sequencing -/alignment-related artefacts [22]. Filter criteria were set by default, except for minimal variant frequency that was changed from 5 to $10 \%$, defining the sensitivity of our SNP calling analysis. To prevent a potential issue for variant calling due to lower coverage of important diagnostic or predictive SNPs (for example TERTp, IDH1/2, $B R A F$, etc.), an additional SNP analysis with SAMtools mpileup was performed.

Vcf files were annotated by annovar [23] with additional information from databases like dbSNP, 1000Genomes Project and COSMIC as well as SIFT and PolyPhen scores to deviate possible biological relevance. Every called InDel was visually checked for plausibility using the Integrative Genomics Viewer (IGV) software [24]. LOH analysis was performed with a self-made filtering using the SNP VCF-file from VarScan somatic. To filter heterozygous SNPs, variant frequencies from normal samples between 30 
and $60 \%$ were applied. Further filtering criteria were more than 20 alternative reads in the normal sample and more than 20 reads in sum in the tumor sample. A ratio of tumor variant frequency and normal variant frequency higher than 1.35 and lower the 0.67 was considered as $\mathrm{LOH}$ [25].

To identify somatic CNV, VarScan copynumer and copyCaller with matched blood or FFPE normal samples were used and data were visualized with the $\mathrm{R}$ bioconductor package DNAcopy [26]. CNV results for broad chromosomal regions and genes were generated separately. Baseline was assessed individually for every sample, based on sorting segments according to their size. $\mathrm{LOH}$ analysis results were also considered. For CNV analysis of chromosomal regions baseline plus/minus 0.4 was considered as balanced. Chromosomal regions with gene dosage increases of more than +0.4 were declared as amplified, whereas regions with gene dosage decreases of more than -0.4 were considered as lost. CNV alterations of genes were considered as relevant starting with at a cut-off of 0.5. Gene segments with dosages more than 1 above the baseline were considered as highcopy amplifications and those with dosages below 1 as homozygous losses. All results generated in this way were visualized with the oncoprint tool provided by the complex heatmap package from R [27] (Figs. 1 and 2).

\section{Validation methods}

Classical diagnostic markers (IDH1/2, H3F3A, BRAF and $1 \mathrm{p} / 19 \mathrm{q} \mathrm{LOH}$ ) were assessed according to qualitycontrolled protocols established in our lab [28]. Briefly, hotspot mutations in $I D H 1 / 2, H 3 F 3 A$ and $B R A F$ were analyzed with direct sanger sequencing after PCR-based amplification of the locus with PCR. 1p/19q LOH was assessed by microsatellite PCR. To validate other SNPs and small InDels detected with the NGS approach, we used direct sanger sequencing following region-specific PCR. Oligonucleotides are listed in Suppl. Table 2. TERTp mutations were detected using the oligonucleotides and protocol described in [29]. PCR reactions were performed using the HotStar Taq DNA Polymerase (Qiagen) and sequencing with the BigDye Terminator v1.1 Cycle Sequencing Kit (Thermo Fisher Scientific) on the SeqStudio Genetic Analyzer (Thermo Fisher Scientific), all according to manufacturers' protocols. For validation of EGFR highcopy amplification and CDKN2A homozygous deletion, a target specific quantitative PCR was performed as described in [30]. For further validation of our $\mathrm{CNV}$ analysis, an OncoScan CNV Assay (Thermo Fisher Scientific) was performed externally as a contract work for 8 selected cases (IMGM Laboratories, Munich). 7 cases were selected because of their high amount of $\mathrm{CNV} / \mathrm{LOH}$ variations and 1 case lacking $\mathrm{CNV} / \mathrm{LOH}$ variations was included as a negative control.
To determine assay performance, test accuracy, sensitivity (true positive rate) and specificity (true negative rate) were calculated according to [31].

\section{Results}

Precision and reliability of the targeted NGS approach

We analyzed 104 CNS tumors classified according the WHO 2016 classification criteria [1]. Entities included and commonly occurring variations for each entity are summarized in Table 1. Variations could be detected in the range of the expected frequencies [1]. Sequencing results of all cases together with additional clinical information are listed in Suppl. Table 3 and visualized in an oncoprint figure (Fig. 1). DNA panel sequencing was robust with a mean of $87.6 \%$ target regions covered with at least 10 reads for all cases analyzed (Suppl. Table 3). Coverages showed a weak positive correlation to the DNA quality value (DIN) measured with an automated electrophoresis tool (TapeStation, Agilent). The few cases (8) with coverages below $80 \%$ also had low DIN values $(<3.5)$ (Suppl. Figure 4).

As prior to panel sequencing for all 104 cases molecular information had been obtained for targets such as IDH1, IDH2, BRAF, H3F3A mutation and 1p/19q loss by means of single molecular assays within the routine diagnostic procedure, this information could be directly compared. All other commonly occurring variations within the different entities were subsequently validated by use of direct sanger sequencing and quantitative PCR. For quality assurance approval of our assay according to the ILAC (DAkkS) standards for inspection bodies (ISO/ IEC 17020) [32, 33], we defined a QC (quality control) cohort of 17 cases comprising 4 astrocytic gliomas, $I D H$ mutant (WHO grade II/III/IV); 2 oligodendrogliomas, $I D H$-mutant and $1 \mathrm{p} / 19 \mathrm{q}$-codeleted (WHO grade III); 5 astrocytic gliomas, $I D H$-wildtype, including 3 glioblastomas (WHO grade IV) and 1 diffuse midline glioma, H3K27M-mutant (WHO grade IV); 4 meningiomas (WHO grade I/II/III) and 2 medulloblastomas (WHO grade IV), 1 WNT-activated and $1 \mathrm{SHH}$-activated. For these 17 cases we validated the majority of all detected SNPs and small InDels. To validate our CNV and $\mathrm{LOH}$ results, DNA panel results of 8 out of the 17 cases were compared to an OncoScan CNV analysis. Validations results for all cases analyzed are summarized in Suppl. Table 4. Examples of the validation procedures are shown for an oligodendroglioma, $I D H$-mutant and $1 \mathrm{p} /$ 19q-codeleted in Suppl. Figure 2 and for a glioblastoma, $I D H$-wildtype in Suppl. Figure 3.

Overall performance of our NGS panel was determined by sensitivity and specificity (Table 2). For the classical diagnostic biomarkers $I D H 1 / 2$ mutation, $1 \mathrm{p} / 19 \mathrm{q}$ loss, BRAF and $H 3 F 3 A$ mutation, sensitivity and specificity were both $100 \%$. For TERTp mutation, EGFR 


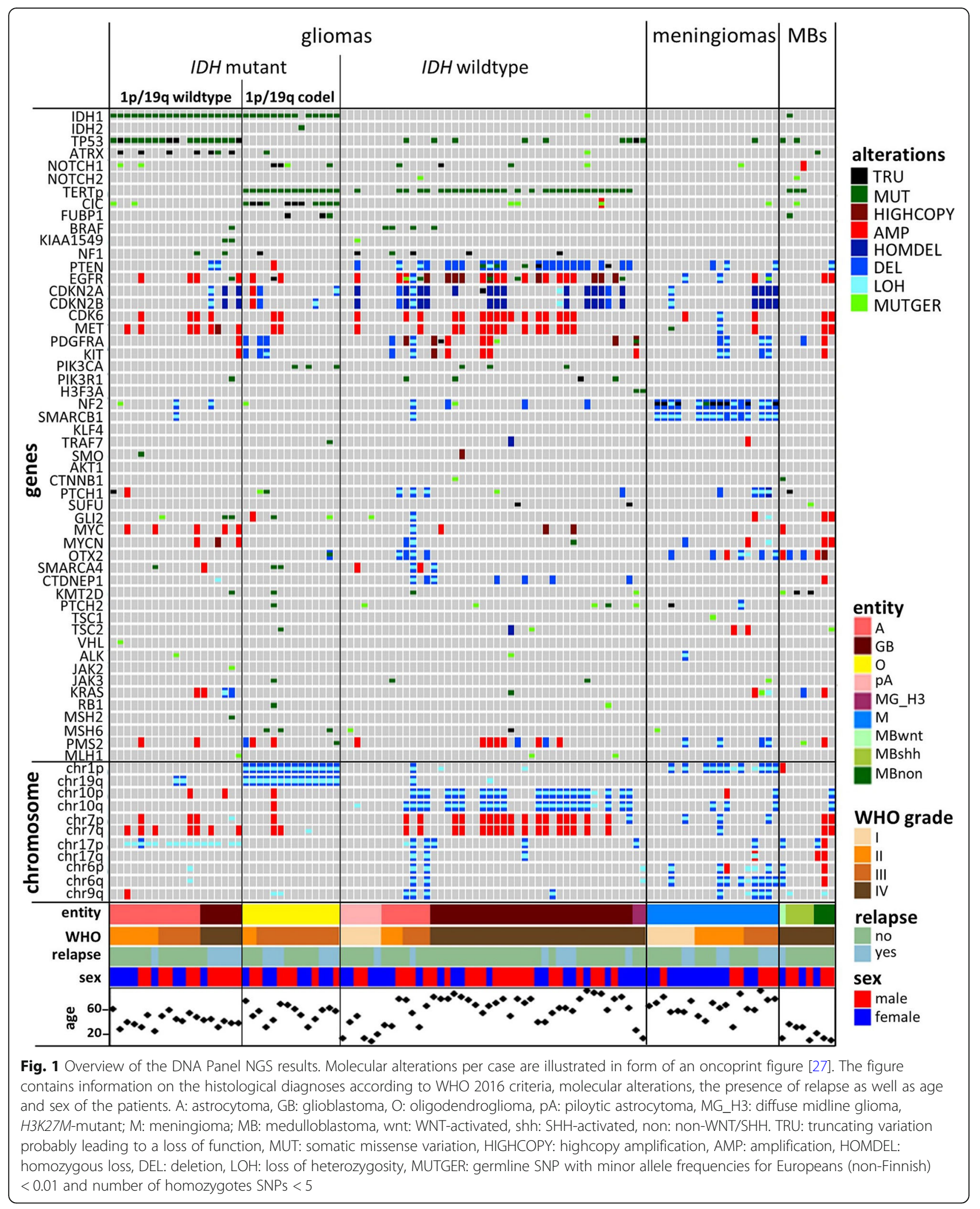




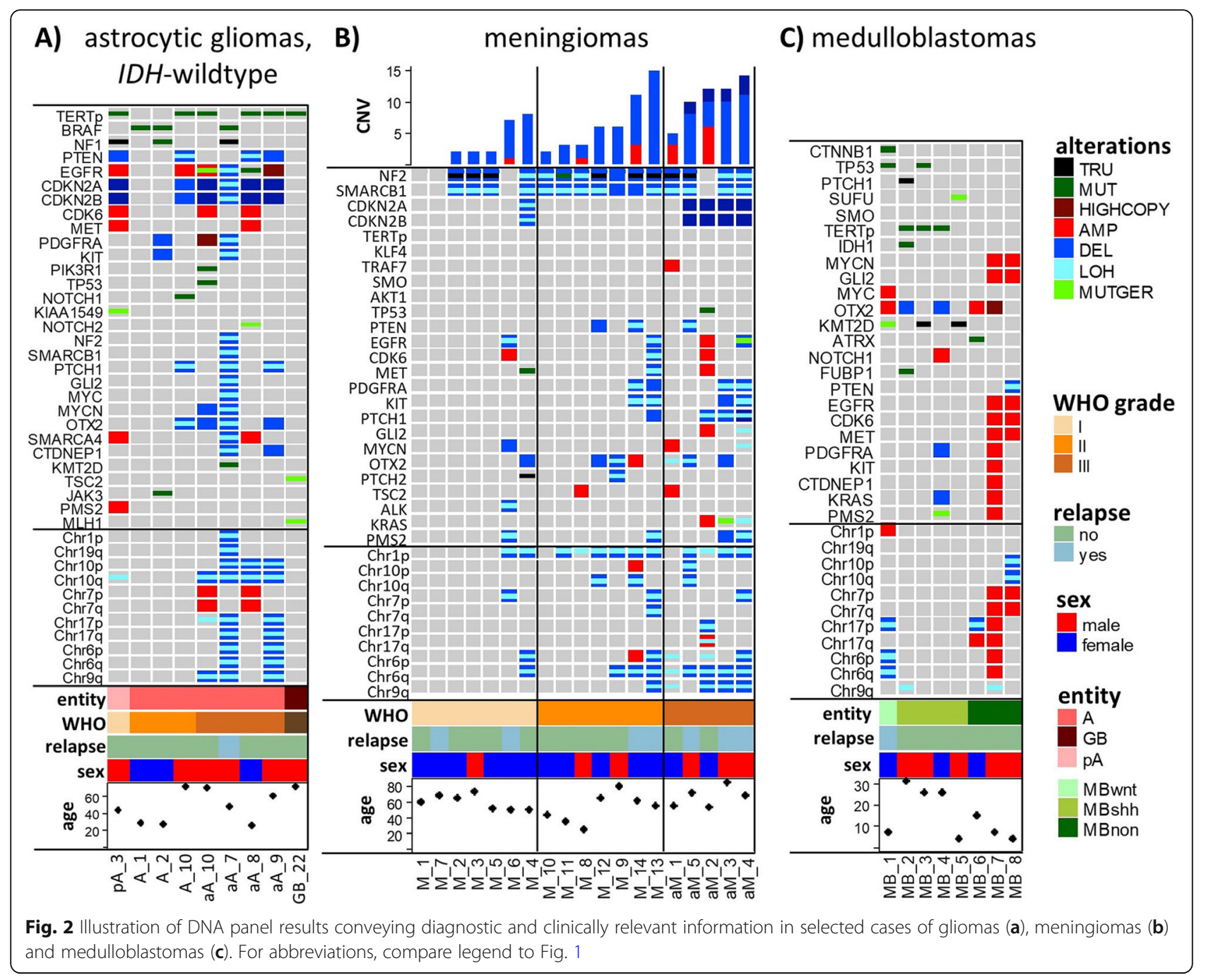

highcopy amplification and $C D K N 2 A$ homozygous deletion (recommended as upcoming diagnostic markers in the cIMPACT now update 3 [2] and in a novel grading system for $I D H$-mutant astrocytomas [3]) clinical sensitivity and specificity was equally $100 \%$. Thus, these main diagnostic markers can be analyzed with the identical sensitivity and specificity in our NGS approach as compared to single gene assay techniques.

Other SNPs and small InDels validated in our QC cohort achieved a sensitivity of $100 \%$ (in this context we abstained from validating negative results due to the multitude of alterations). For our LOH analyzes a sensitivity of $90 \%$ and specificity of $97 \%$, and for CNV analysis a sensitivity of $94 \%$ and specificity of $97 \%$ were achieved. To determine diagnostic test accuracy, we performed NGS panel analysis in two independent cycles with 3 cases out of the 17 obtaining identical results. Here, we achieved $100 \%$ accuracy for the SNP and small InDels calling analysis, for $\mathrm{LOH}$ analysis as well as for the $\mathrm{CNV}$ analysis.
Taken together, our targeted NGS approach proved precise and reliable with 100\% accuracy, 97\% sensitivity and $98 \%$ specificity.

\section{Diagnostic implications in gliomas}

77 astrocytic and oligodendroglial tumors were analyzed on our new platform (for detailed information see above). While the initial 42 cases had been evaluated for validation purposes, the subsequent 35 cases were analyzed within a diagnostic and clinical context. Out of these 35 cases, 9 received a refined diagnosis or even reclassification after consideration of the molecular data resulting from NGS panel sequencing. Thus, $26 \%$ of patients (more than every fourth) benefited from in-depth molecular analysis. Context situations of diagnosis refinement were as follows:

Our cohort contained 3 diffuse and 4 anaplastic $I D H$ wildtype astrocytomas that are considered as a provisional entity for which diagnosis is discouraged. 
Table 1 Overview of all cases analyzed and entity specific alterations with frequencies

\begin{tabular}{|c|c|c|c|c|}
\hline Entity & \# & Aberrations & $\#$ & Frequency \\
\hline \multirow[t]{4}{*}{ Astrocytic glioma, IDH-mutant (WHO grade II/III/IV) } & \multirow[t]{4}{*}{19} & $\mathrm{IDH} 1 / 2$ & 19 & $100 \%$ \\
\hline & & TP53 & 18 & $95 \%$ \\
\hline & & ATRX & 7 & $37 \%$ \\
\hline & & CDKN2A HomDel & 2 & $11 \%$ \\
\hline \multirow{5}{*}{$\begin{array}{l}\text { Oligodendroglioma, IDH-mutant 1p/19q-codeleted } \\
\text { (WHO grade II/III) }\end{array}$} & \multirow[t]{5}{*}{14} & $\mathrm{IDH} 1 / 2$ & 14 & $100 \%$ \\
\hline & & $1 p / 19 q \mathrm{LOH}$ & 14 & $100 \%$ \\
\hline & & TERTp & 14 & $100 \%$ \\
\hline & & $\mathrm{ClC}$ & 11 & $79 \%$ \\
\hline & & FUBP1 & 4 & $29 \%$ \\
\hline \multirow[t]{6}{*}{ Astrocytic glioma, IDH-wildtype (WHO grade I/II/II/IV) } & \multirow[t]{6}{*}{42} & TERTp & 30 & $71 \%$ \\
\hline & & 10 DEL / 7 AMP & 14 & $33 \%$ \\
\hline & & EGFR Highcopy & 9 & $21 \%$ \\
\hline & & TP53 & 9 & $21 \%$ \\
\hline & & NF1 & 5 & $12 \%$ \\
\hline & & BRAF & 4 & $10 \%$ \\
\hline \multirow[t]{2}{*}{ Diffuse midline glioma, H3K27M-mutant (WHO grade IV) } & \multirow[t]{2}{*}{2} & $\mathrm{H} 3 \mathrm{~F} 3 \mathrm{~A}$ & 2 & $100 \%$ \\
\hline & & TP53 & 2 & $100 \%$ \\
\hline \multirow[t]{5}{*}{ Meningioma (WHO grade $|/||/| I I)$} & \multirow[t]{5}{*}{19} & NF2 & 15 & $79 \%$ \\
\hline & & SMARCB1 & 15 & $79 \%$ \\
\hline & & $1 p$ DEL & 12 & $63 \%$ \\
\hline & & CDKN2A HomDel & 4 & $21 \%$ \\
\hline & & TERTP & 0 & $0 \%$ \\
\hline \multirow[t]{6}{*}{ Medulloblastoma (WHO grade IV) } & \multirow[t]{6}{*}{8} & TERTp & 3 & $38 \%$ \\
\hline & & TP53 & 2 & $25 \%$ \\
\hline & & OTX2 Highcopy & 1 & $13 \%$ \\
\hline & & CTNNB1 & 1 & $13 \%$ \\
\hline & & Monosomy 6 & 1 & $13 \%$ \\
\hline & & Isochromosome 17 & 1 & $13 \%$ \\
\hline
\end{tabular}

AMP: amplification, DEL: deletion, Highcopy: highcopy amplification, HomDel: homozygous loss, LOH: loss of heterozygosity

Indeed, panel sequencing enabled reclassification of these cases. 4 tumors (A_10, aA_8, aA_9 and aA_10; Fig. 2a) contained prognostically relevant alterations as highlighted in the recent cIMPACT-NOW update 3 [2]. By the presence of TERTp mutations, EGFR highcopy amplification and/or combined gains or losses of whole chromosome 7 and 10 these tumors could be reclassified as diffuse astrocytic gliomas, $I D H$-wildtype, with molecular features of glioblastoma. Thereby, the tumors could be assigned to a WHO grade IV, impacting subsequent therapeutic strategies. The other $3 \mathrm{IDH}$-wildtype astrocytomas (A_1, A_2, aA_7; Fig. 2a and Suppl. Figure 5) were reclassified due to miscellaneous reasons:

Tumor A_1 showed no additional alterations except for a BRAF (p.V600E) mutation. Close histological reevaluation revealed irregularly arranged neuronal elements at the periphery of the lesion, highlighted by antibodies to synaptophysin and neurofilament. Moreover, CD34-immunostaining identified peritumoral satellite cells. These findings led to the revised integrated diagnosis of ganglioglioma (WHO grade I).

Tumor A_2 was the case of a 27 years old patient with an intra- and periventricular brain lesion involving the basal ganglia. Detection of a BRAF V600E mutation next to mutations in NF1 and JAK3 as well as deletions of KIT and PDGFRA led to the diagnosis of a pediatrictype low-grade glioma or ganglioglioma. A parallel $850 \mathrm{k}$ methylation array analysis also achieved the highest score (0.51) for low-grade gliomas, in particular the subclass of gangliogliomas.

Tumor aA_7 exhibited multiple losses of chromosomal regions, homozygous deletion of $C D K N 2 A / B$ and a particular mutation of BRAF (p.D594G) by NGS analysis. With these findings -even in absence of typical 
Table 2 Validations performed for quality control according to the ILAC (DAkkS) standards for inspection bodies (ISO/IEC 17020)

\begin{tabular}{|c|c|c|c|c|c|c|}
\hline & Abberation & \# Cases & \# Validations & Validation method & Sensitivity & Specificity \\
\hline \multirow[t]{7}{*}{ Single assay validation } & $\mathrm{IDH} 1 / 2$ & 34 & 68 & Sanger seq. & $100 \%$ & $100 \%$ \\
\hline & $1 p / 19 q \mathrm{LOH}$ & 15 & 35 & Microsatellite PCR & $100 \%$ & $100 \%$ \\
\hline & BRAF V600 & 2 & 3 & Sanger seq. & $100 \%$ & $100 \%$ \\
\hline & $\mathrm{H} 3 \mathrm{~F} 3 \mathrm{~A}$ & 2 & 3 & Sanger seq. & $100 \%$ & $100 \%$ \\
\hline & TERTp & 47 & 50 & Sanger seq. & $100 \%$ & $100 \%$ \\
\hline & CDKN2A HomDel & 8 & 11 & quantitative PCR & $100 \%$ & $100 \%$ \\
\hline & EGFR Highcopy & 12 & 14 & quantitative PCR & $100 \%$ & $100 \%$ \\
\hline \multirow[t]{3}{*}{ QC cohort } & other SNPs / InDels & 17 & 28 & Sanger seq. & $100 \%$ & n.d. \\
\hline & other $\mathrm{LOH}$ & 8 & 28 & Oncoscan Array & $90 \%$ & $97 \%$ \\
\hline & all CNVs & 8 & 47 & Oncoscan Array & $94 \%$ & $97 \%$ \\
\hline Overall performance & & & & & $97 \%$ & $98 \%$ \\
\hline
\end{tabular}

DNA panel results were compared to quality-controlled single assays in our routine diagnostic lab for the established molecular biomarkers $I D H 1 / 2, B R A F$ and H3F3A mutation as well as $1 p / 19 q$ codeletion. TERTp mutations, CDKN2A homozygous deletions and EGFR highcopy amplifications were validated by direct sanger sequencing or quantitative PCR. Intensified quality assurance approval was performed in a cohort of 17 tumors. In these cases, the majority of detected SNPs and small InDels were reanalyzed using direct Sanger sequencing. Other LOH results and CNV results were reanalyzed using an OncoScan CNV analysis. Comparison of DNA panel and validation results yielded excellent sensitivity and specificity. n.d.: negative results were not validated, QC: quality control cohort

histological features as lipidized cells, a pericellular reticulin network and co-expression of neuronal markerswe reclassified the tumor as anaplastic pleomorphic xanthoastrocytoma (WHO grade III). Though, in pleomorphic xanthoastrocytomas most of the BRAF mutations are of the V600E type, exceptions as in the present case are well documented [34]. DNA methylation-based analysis of aA_7 showed elevated scores for pilocytic astrocytoma and BRAF-mutant low-grade glioma but could not finally classify the lesion.

Apart from reclassifying $I D H$-wildtype astrocytomas, panel sequencing contributed to clarifying the difficult differential diagnosis between reactive gliosis and glioma infiltration in biopsy samples of limited glial cell density and confined p53 immunoreactivity. In GB_22 (Fig. 2a), detection of a TERTp mutation pointed to a neoplastic origin of the increased glial cell content resulting in the diagnosis of the infiltration zone of an $I D H$-wildtype glioblastoma.

Finally, panel sequencing identified cases with unusual molecular features and clinical course. On magnetic resonance imaging (MRI) scan, a frontal lobe tumor presented as a poorly defined mass with T2-FLAIR hyperintensity and only very minor gadolinium enhancement, so that a low-grade glioma was suspected. Microscopic analysis disclosed an $I D H$-wildtype astrocytic glioma with only moderate cell density and low Ki67-index (3\%), first classified as pilocytic astrocytoma (pA_3, Fig. 2a). However, in the small specimens, a decisive tumor classification appeared difficult since the morphological features were compatible with pilocytic astrocytoma, but also other pediatric-type gliomas or even low cellular areas of glioblastoma. The absence of KIAA1549-BRAF fusion did not necessarily exclude the diagnosis of a pilocytic astrocytoma. Panel sequencing enabled the detection of a TERTp mutation, a loss of function mutation in the NF1 gene, a homozygous deletion of CDKN2A, and LOH on chromosome 10q along with deletion of PTEN. This would be a rather unusual molecular constellation for pilocytic astrocytoma. Instead, combined mutations in TERTP, PTEN and NF1 are described for high-grade gliomas and are associated with an unfavorable prognosis $[35,36]$. Not surprisingly, this patient suffered from tumor progression at already 9 months after the first surgery, despite gross total resection.

\section{Prognostic refinement in meningiomas}

We analyzed 19 meningiomas, graded by conventional histology as 7x WHO grade I, 7x WHO grade II and $5 \mathrm{x}$ WHO grade III (Fig. 2b and Suppl. Table 3). The main and most consistent variations detected, as expected, were NF2 truncating mutations and/or deletions/LOH of the NF2 gene locus [37]. As can be seen from Fig. 2b, complexity of detected CNVs was heterogeneous within the grades and a high $\mathrm{CNV}$ content was not exclusively reserved to WHO grade III meningiomas, but could be also observed in individual WHO grade I and II lesions. In the WHO grade I tumor group, for example, 2 meningothelial meningiomas (M_4 and M_6, Fig. 2b) showed 8 and $7 \mathrm{CNV}$ variations, respectively, compared to 0 to 2 variations detected in the other WHO grade I tumors. One of these cases (M_4, WHO grade I) had a $1 \mathrm{p}$ and an additional $C D K N 2 A / B$ loss, both described as prognostic unfavorable molecular alterations $[1,6]$. Indeed, the respective patient exhibited a poor clinical course with tumor progression after 17 months, despite 
gross total tumor resection (Simpson grade 1) and a tumor size of only $41 \mathrm{~mm}$ without sinus infiltration.

In the WHO grade II group, we identified a tumor with a very high number of 14 CNVs (M_13, Fig. 2) and a prognostically unfavorable $1 \mathrm{p}$ loss. Also for that case, the respective clinical course was poor with a tumor progression after 10 months, despite a gross total tumor resection (Simpson grade 1) and a tumor size of $88 \mathrm{~mm}$ without sinus infiltration.

Thus, the detection of prognostically unfavorable alterations and the appreciation of the complexity of CNVs can help to identify patients with a higher risk of recurrence in the group of benign WHO grade I and prognostically heterogeneous WHO grade II meningiomas.

\section{Subtyping of medulloblastomas}

We analyzed 8 medulloblastoma that had been subtyped with an immunohistochemical approach [10]: 1 WNTactivated, 4 SHH-activated (3 TP53-wildtype and 1 TP53-mutant) and 3 non-WNT/non-SHH-activated cases (Fig. 2c and Suppl. Table 3). With our targeted DNA panel sequencing approach, subgroups could be retraced in all cases by identifying alterations of typical pathway genes:

The WNT-activated medulloblastoma (MB_1) showed characteristic variations specific for this subgroup, like a CTNNB1 mutation and chromosome 6 monosomy [8]. In the $\mathrm{SHH}$-activated medulloblastoma cases, $2 \mathrm{SHH}$ pathway specific mutations in SUFU (MB_5) or PTCH1 (MB_2) were detected. 3 of the $4 \mathrm{SHH}$-activated medulloblastomas harbored a TERTp mutation (MB_2, MB_3, MB_4), which has also been described as a variation specific for $\mathrm{SHH}$-activated medulloblastomas [1, 38]. Interestingly, one of the cases (MB_2) was a rare $\mathrm{SHH}$ activated medulloblastoma showing an IDH1:p.R132C mutation. Of the 4 cases described harboring such a mutation 3 fell into the $\mathrm{SHH}$-activated subgroup of medulloblastomas [12]. Non-WNT/SHH-activated medulloblastomas are less well characterized in terms of pathway activation [39]. Nevertheless, there are some characteristic CNVs for this subgroup detected with our DNA panel analysis, like isodicentric chromosome 17q (MB_6), chromosome 17q amplification (MB_7) and chromosome 7 amplification (MB_7 and MB_8) [12].

\section{Identification of actionable mutations for individualized treatment approaches}

Genes were referred to as targetable or resistancemediating according to ICGC (the international cancer genome consortium) or CIVIC (clinical interpretations of cancer variants from the McDonnell Genome Institute at Washington University School of Medicine) if there was proven/consensus association in human medicine or evidence from clinical trials, case reports or other primary data in brain tumors or other cancer entities [14, 15] (Suppl. Table 1).

Of the 104 cases that were analyzed on our platform 60 cases were used for establishing the assay and for validation purposes. 44 cases were analyzed on clinical request. Of note, 22 out of these 44 cases (50\%) showed putatively targetable or resistance-mediating variations with $E G F R, C D K 6$ and $M E T$ aberrations most frequently detected (Fig. 3b).

After careful revision by a group of clinicians (neurooncologist, neurosurgeon, medical oncologist) 3 patients were chosen for an individualized therapy based on molecular data generated by our NGS approach (Table 3). Only patients in a relatively good condition for which standard therapeutic approaches were exhausted were selected from the clinical side. These patients' tumors then had to harbor molecular variations with clear therapeutical relevance and sufficient variant frequencies from the neuropathological side explaining the low number of patients included into this algorithm so far. The case histories of the three patients were as follows:

Patient 1 was a 33-year old male (sGB_6) diagnosed with astrocytoma, $I D H$-mutant (WHO grade II) and relapse with a secondary glioblastoma without MGMT methylation. Based on panel sequencing results with amplification of MET and KIT and tumor board decision, cabozantinib was initiated in a dose of $100 \mathrm{mg}$ daily in the third relapse of the disease. The patient showed a very good clinical response with a recovery to almost normal and a good partial response on MRI which was sustained for 6 months (Fig. 3, c-d). Response was achieved without further surgery and solely based on the targeted therapy. After 6 months of Cabozantinib, the patient progressed clinically and on MRI. Treatment was terminated and the patient died another 3 months later in hospice care. In summary, overall survival with glioblastoma was 20 months, and progression free survival with Cabozantinib was 6 months.

Patient 2 was a 31-year old male (MB_2) diagnosed with medulloblastoma, SHH-activated and TP53-wildtype (WHO grade IV), and presenting with an unusual relapse involving the nuchal lymph nodes but not the primary site. Lymph nodes were biopsied and histology proved dissemination of a medulloblastoma. Based on panel sequencing results with a PTCH1 loss of function mutation combined with a $\mathrm{LOH}$ (variant frequency: 92\%) and tumor board decision, vismodegib was initiated in a dose of $150 \mathrm{mg}$ daily in combination with temozolomide. The patient showed a good partial response and terminated temozolomide after 6 months and vismodegib after 12 months of treatment. A year later he presented with enlarged lymph nodes in his right axilla and mediastinum and with a local 


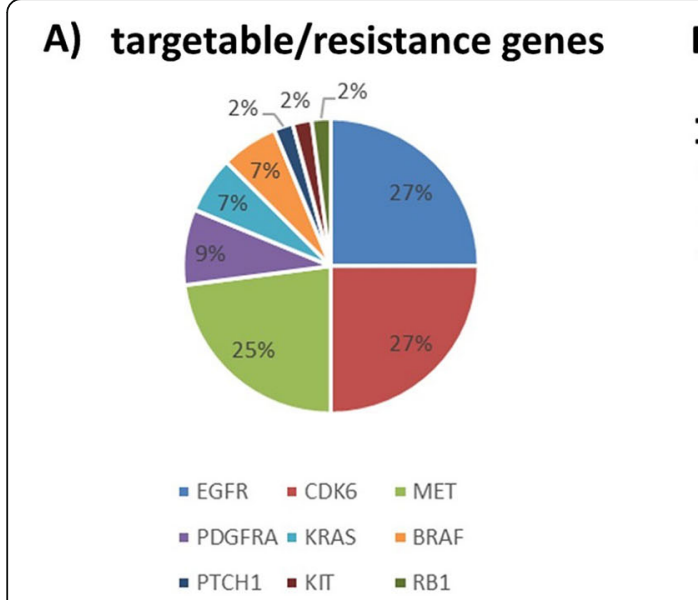

\section{C) sGB_6, MRI : 28.02.2019}

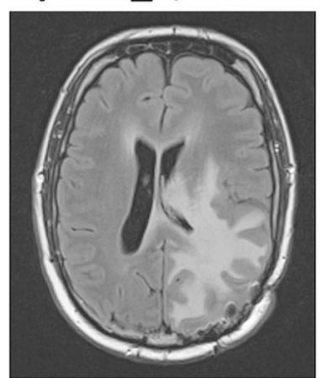

T2/flair

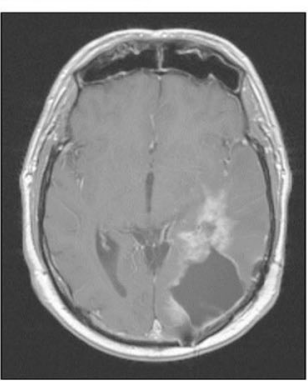

\section{D) sGB_6, MRI : 05.06.2019}

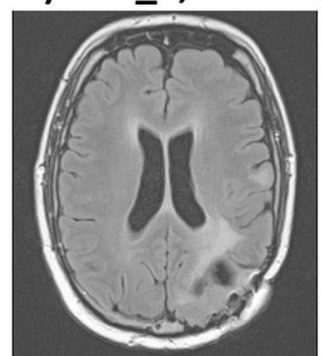

T2/flair

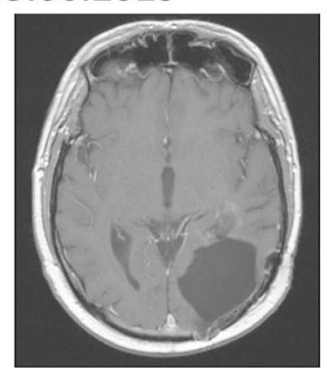

T1 + contrast
B)

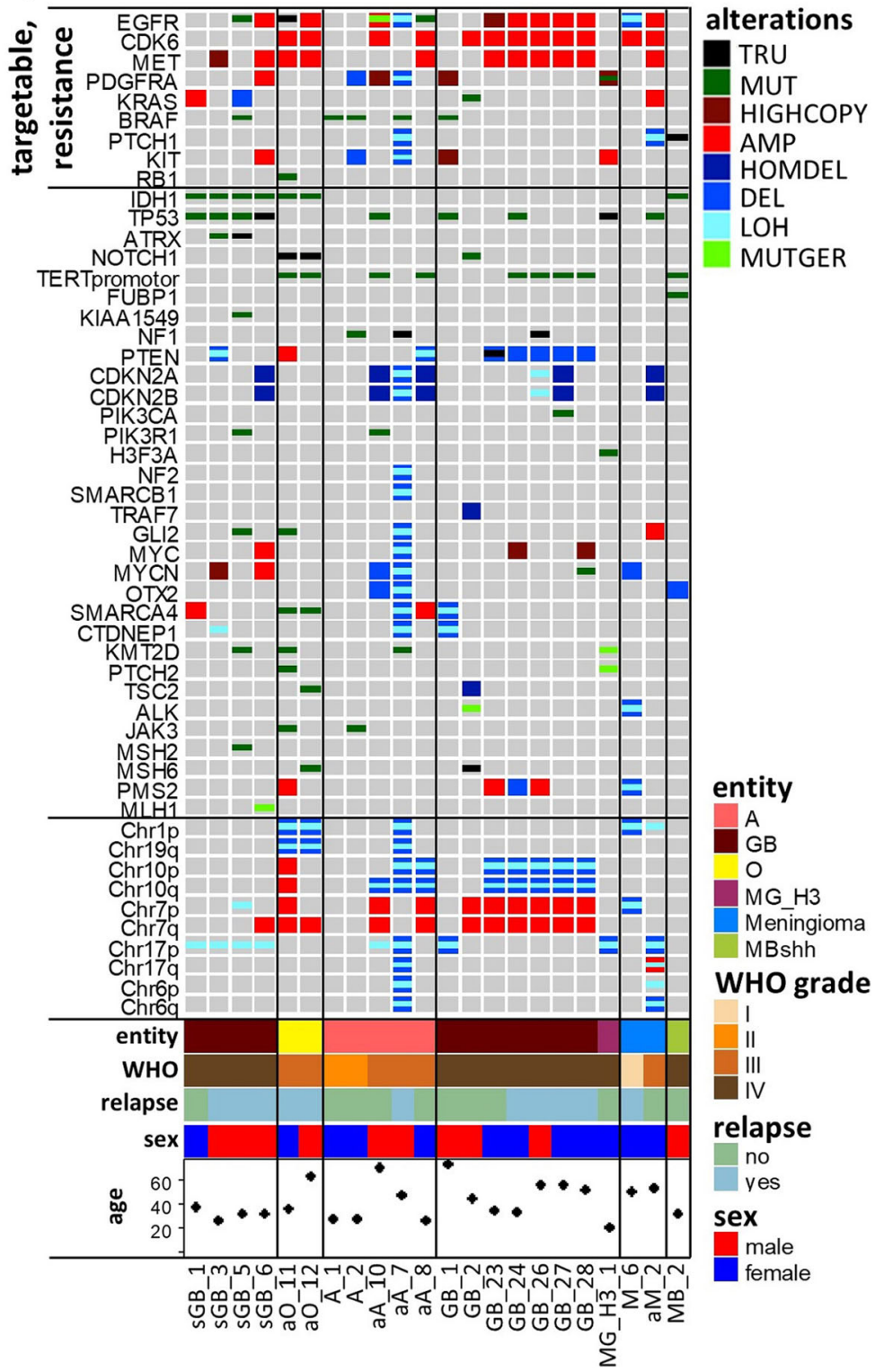

Fig. 3 Targeted therapy based on DNA panel sequencing results. (a) Frequencies of putatively targetable and therapy resistance-mediating variations within the clinically requested cohort. (b) Shown is the full spectrum of molecular alterations in all cases containing targetable and resistance-mediating variations in form of an oncoprint fig [27]. For abbreviations, compare legend to Fig. 1. (c) MRI of sGB_6 shows one region of extended hyperintensity (FLAIR) and a further region with notable contrast enhancement in T1 before starting individualized therapy. (d) After two cycles of therapy, hyperintensity (FLAIR) was clearly diminished and contrast enhancement almost completely disappeared, indicating partial response. Images were chosen on the levels of maximum lesions, as it would also be done for evaluation of the neuroradiological RANO criteria, that are standard for the evaluation of tumor treatment responses in gliomas [40]

relapse at the primary site in the cerebellum. The axillar and mediastinal lymph nodes were irradiated with 54Gy, and temozolomide was combined with sonidegib $200 \mathrm{mg}$ daily, based on the superior pharmacokinetic data for sonidegib in comparison to vismodegib. The patient again showed a good partial response in his lymph nodes and a complete response at his primary site in the cerebellum after 3 months of treatment. In summary, overall survival was 43 months after diagnosis, progression free survival in the first relapse under treatment with vismodegib and temozolomide was 15 months, and a second partial response was noted under sonidegib plus temozolomide, which was sustained at the time of this report (10 months). 
Table 3 Information on patients that received a targeted therapy based on DNA panel sequencing results

\begin{tabular}{lllll}
\hline $\begin{array}{l}\text { Patient } \\
\text { ID }\end{array}$ & Entity & Therapeutic & Description & Target \\
\hline SGB_6 & Secondary glioblastoma, IDH-mutant (WHO grade IV) & Cabozantinib & $\begin{array}{l}\text { Tyrosine kinase } \\
\text { inhibitor }\end{array}$ & MET AMP, KIT AMP \\
MB_2 & Medulloblastoma, SHH-activated/TP53-WT (WHO grade IV) & $\begin{array}{l}\text { Vismodegib/ } \\
\text { sonidegib }\end{array}$ & $\begin{array}{l}\text { Sonic hedgehog } \\
\text { pathway inhibitor }\end{array}$ & $\begin{array}{l}\text { PTCH1 stopgain with a } \\
\text { frequency of 92\% }\end{array}$ \\
aA_8 & Anaplastic astrocytoma, IDH-wildtype (WHO grade III) & Abemaciclib & CDK4/6 inhibitor & CDK6 AMP \\
& $\begin{array}{l}\text { reclassified as: } \\
\text { Diffuse astrocytic glioma, IDH-wildtype, with molecular } \\
\text { features of glioblastoma (WHO grade IV) }\end{array}$ & & \\
\hline
\end{tabular}

Patient 3 was a 26-year old female patient (aA 8) diagnosed with anaplastic astrocytoma, $I D H$ wildtype (WHO grade III) without MGMT promoter methylation. By DNA panel sequencing the tumor was reclassified as diffuse astrocytic glioma, $I D H$-wildtype, with molecular features of glioblastoma (WHO grade IV, see above). Based on panel sequencing with a CDK6 amplification and decision of our interdisciplinary tumor board, abemaciclib in combination with temozolomide was initiated in the fourth relapse. At the beginning of abemaciclib, the patient was in a good self-containing state. She deteriorated slowly during abemaciclib and temozolomide in her MRI and clinical status, and the therapy was terminated 3 months later. In summary, overall survival was 33 months, and abemaciclib and temozolomide did not generate an objective response or stabilization of disease. Possible reasons for the lack of response in this case may be the late administration of the targeted agent in the fourth relapse and a very large tumor volume on MRI.

Taken together, at least the first two case reports indicate that selected patients may benefit from molecularly driven approaches as derived from our panel sequencing assay even when standard therapies are exhausted.

\section{Discussion}

The rapid evolution of meaningful molecular markers in brain tumor classification and therapy poses challenges to many neuropathology labs. When thinking about a suitable way to address the increasing number and complexity of alterations that have to be tested for, we made the following considerations: We wanted to establish a single platform approach that would allow for the parallel detection of diagnostically and therapeutically relevant markers. The approach should be cost-efficient, on an in-house platform and quality-controlled. It should fit into our lab's molecular workflow and present with acceptable turnaround times to not delay patients' clinical management. The NGS panel sequencing assay presented here fulfills these requirements. Our customized amplicon capture-based based approach allows detection of molecular alterations with high specificity and accuracy. Accuracy was $100 \%$, sensitivity $97 \%$ and specificity $98 \%$, leading to quality assurance approvement according to the ILAC (DAkkS) standards for inspection bodies (ISO/IEC 17020) [32, 33]. It can be run on the relatively cost-efficient Illumina MiniSeq platform with a 5-day workflow from DNA isolation to bioinformatic analysis and the molecular report (Suppl. Figure 1).

In terms of the diagnostic surplus value we could show that NGS panel sequencing leads to diagnostic refinement or reclassification in about a fourth of gliomas, identifies molecularly suspect meningiomas with an unfavorable clinical course and allows for the precise subclassification of medulloblastomas. Moreover, it identifies actionable mutations of clinical use in a relevant fraction $(50 \%)$ of patients that can be exploited for successful targeted approaches.

A number of NGS-based approaches for brain tumor diagnostics have been reported so far, showing similarities but also differences to our findings [13, 41-46]. Most of the publications emphasize the diagnostic benefit as well as the future surplus value for targeted therapies. Interestingly, one of the other panel sequencing approaches evaluating data on a large series of 433 gliomas [44] -identically to our observations- reports on a fraction of about a fourth of cases with refined diagnoses. In terms of the composition of genetic alterations included and the technical realization, however, there are large differences between the reported assays. The group in [13], for example, uses a similar library preparation technique as we do, but runs a larger panel on a NextSeq 500 platform that is primarily focused on the detection of actionable mutations. The group in [45] employs a completely different library preparation method and sequencing technique based on the Ion Torrent (PGM) platform.

The assay presented here is unique as it also allows for the parallel assessment of SNPs, InDels, CNV and LOH with the latter based on the comparison of oftenmutated SNPs between tumors and matched normal controls. This widens the functionality of our panel in more complex diagnostic context situations such as medulloblastoma subclassification or identification of 
cIMPACT-NOW update 3 alterations. The necessity to analyze matched patients' blood samples may be beneficial also in another respect. It allows for the sure identification of somatic variations without any possible germline contaminations what we would consider recommendable for this type of analysis anyway, independent on whether LOH analyzes are performed or not. In our cohort germline variations misinterpreted as somatic mutations would have led to false positive results in 37\% of the cases. Incidentally observed, tumor-relevant germline variations can be reported in collaboration with human genetics according to mandatory legal requirements. Another significant difference of our assay in comparison to others is the cross-entity suitability including alterations relevant to gliomas, meningiomas and medulloblastomas. In our perception this has a number of advantages, particularly in smaller labs with fewer NGS requests. First, in terms of efficiency, it allows us to focus on only one library preparation approach and to smoothly pool the libraries on the same flow cell. This decreases turnaround times as every NGS order fills the flow cell independently of the underlying diagnosis. Moreover, we have also included alterations like C19MC amplification in our panel. Having this in store as a single molecular, e.g. FISH assay, would not be cost-efficient as due to the very low commissioning frequency of the assay, probes would expire before they are used up. By inclusion in our comprehensive panel approach we can hold the marker in store and run the analysis whenever indicated. Finally, the combination of multiple alterations in our assay supports differential diagnoses and has synergistic effects in terms of alterations that contain both diagnostic and predictive informational content.

However, there are also limitations to our approach. MGMT promoter methylation is a marker that cannot be included in our setting and has to be tested separately. Also, we cannot detect gene fusions, like e.g. KIAA1549:BRAF, RELA:C11ORF95, YAP1, FGFR, MYB1 in a diagnostic or NTRK in a predictive context [47-52]. We are currently working on an RNA-based NGS approach that similarly to the here reported DNA panel will cover a larger spectrum of entities with a focus on pediatric brain tumors. As outlined above, we performed the whole NGS data analysis with freely available, customizable tools on a Linux-based workstation. Set-up of theses algorithms was a time-consuming investment and may be a hurdle for those labs thinking about starting with similar workflows. We also tried a couple of tools that were available by commercial suppliers. These may be well-suited in certain context situations. However, we felt that for a full support of our analysis and for flexible adaptation to our evaluation needs the use of custom-made scripts was indispensable. Once up and running these scripts multiply the informational content and help to exploit the whole potential of the method.

In conclusion, we here describe a targeted NGS-based DNA panel approach that comprehensively addresses the most relevant alterations in molecular neurooncology and may be suited also for implementation in smaller neuropathology labs. Our assay has been extensively validated and proven to convey diagnostic and clinical surplus value. As additional markers can be easily included, the assay can be adapted to the specific requirements of local brain tumor centers and appears future-proof in terms of upcoming revisions of the WHO classification.

\section{Supplementary information}

Supplementary information accompanies this paper at https://doi.org/10. 1186/s40478-020-01000-w.

Additional file 1: Supplementary Table 1. Genes and chromosomal regions included in the targeted DNA panel. Most genes were covered using the CDS, for some well-known mutations only hotspot regions were targeted with SNP/small InDel calling being performed (SNP). Chromosomal regions were covered with commonly heterozygous SNPs for LOH and CNV analyzes. Genes included in LOH and CNV analysis were additionally covered with commonly heterozygous SNPS in intronic regions. Variations of genes and chromosomal regions may either be characteristic for a specific tumor entity (diagnostic), indicate actionable mutations for targeted therapies (targetable) and/ or drug resistance (resistance) or be associated with impaired DDR. CDS: complete coding sequence, CNV: copy number variations, DDR: DNA damage response, $\mathrm{LOH}$ : loss of heterozygosity, SNP: single nucleotide variant.

Additional file 2: Supplementary Table 2. Oligonucleotides used for validation purposes.

Additional file 3: Supplementary Table 3. Tabular survey of all panel sequencing results. Validation cases and clinically requested cases are indicated, also the 17 cases that were used for intensified quality control (QC cohort). HOMDEL: homozygous loss, HIGHCOPY: highcopy amplification, TRU: truncating variation probably leading to a loss of function, MUT: somatic missense variations, LOH: loss of heterozygosity, DEL: deletion, AMP: amplification, MUTGER: germline SNP with minor allele frequency European (non-Finnish) $<0.01$ and number of homozygotes SNPs < 5, DELP/AMPp/LOHp: partial variation of a chromosomal arm.

Additional file 4: Supplementary Table 4. Tabular survey of validation results to determine DNA panel sequencing performance. SNPS and InDels were validated with direct Sanger sequencing, 1p/19q codeletions with microsatellite PCR analysis, and homozygous deletion of CDKN2A as well as highcopy amplification of EGFR with target specific quantitative PCR. Medulloblastoma subgroups were validated by comparison to immunohistochemically determined subgroups with antibodies against ß-Catenin, Yap1, p75-NGFR and OTX2 [10]. InDel: small insertion/deletion, nd: not determined, RET: retention, SNP: single nucleotide variant, WT: wildtype.

Additional file 5: Supplementary Figure 1. 5-day DNA panel sequencing workflow

Additional file 6: Supplementary Figure 2. Validation example for an anaplastic oligodendroglioma, IDH-mutant and 1p/19q-codeleted (aO_1). DNA panel result of the IDH1:p.R132H mutation visualized in IGV (A) and corresponding direct sanger sequencing (B). DNA panel results of $\mathrm{LOH}$ analysis using commonly occurring SNPs compared to matched blood (C). Corresponding $\mathrm{LOH}$ analysis using microsatellite analysis with fluorescence marked oligonucleotides compared to matched blood (D) The results for one marker on chromosomal arm 1p (D1S513) and one 
on 19q (D19S572) are shown exemplarily. IGV: integrative genomic viewer, LOH: loss of heterozygosity.

Additional file 7: Supplementary Figure 3. Validation example for the CNV analysis in a case of glioblastoma, IDH-wildtype (GB_17). DNA panel results of the CNV analysis for chromosomal regions $(\bar{A})$ and genes (B) were compared to a corresponding OncoScan CNV analysis (C). CNV: Copy number analysis.

Additional file 8: Supplementary Figure 4. Correlation of coverage with DNA quality. Percentages of target regions covered with at least 10 reads were plotted against the DIN value on a tumor by tumor basis. DIN values were measured with an automated electrophoresis tool (Tapestation 4200, Agilent). Higher DIN values indicate an intact, not degraded DNA and lower DIN values a degraded DNA of low quality. A weak ( $>0.3$ ) positive correlation between coverage and DIN value was observed indicating a dependency of coverage on DIN value.

Additional file 9: Supplementary Figure 5. Preoperative magnetic resonance imaging (MRI) and histology of the IDH-wildtype astrocytomas A_1, A_2 and aA_7. (A) A_1. MRI shows hyperintensity in FLAIR without contrast enhancement in $\mathrm{T} 1$ in the dorsal region of right insula, compatible with a low-grade glioma. Microscopic examination displayed a neuroepithelial lesion of moderate cell density and only low nuclear pleomorphism. Both GFAP and Synaptophysin were strongly expressed. CD34 immunoreactivity was prominent and highlighted peritumoral satellite cells. (B) A 2. MRI shows several contrast enhancing lesions on both sides of the midline with corresponding FLAIR hyperintensity. Histologically, the lesion exhibited features of a low-grade glioma in a slightly fibrillary background. Cellularity was moderate and mitoses or nuclear atypia of higher degree were absent. Singular entrapped neuronal cells were considered to be pre-existing. (C) aA-7. MRI shows a region of corresponding hyperintensity (FLAIR) and contrast enhancement (T1). Histology revealed a highly cellular astrocytic glioma with moderate pleomorphism, variable cell morphology, sometimes fusiform cells and marked aggregation of lymphocytic infiltrates.

\section{Acknowledgments}

We thank Maria Hirblinger, Irene Schardt and Susanne Brüggemann for excellent technical assistance.

\section{Authors' contributions}

Conception and design: Riemenschneider MJ, Lorenz J. Development of methodology: Lorenz J, Riemenschneider MJ. Acquisition of data: Lorenz J, Rothhammer-Hampl T, Zoubaa S, Bumes E, Proescholdt M, Hau P. Analysis and interpretation of data: Lorenz J, Rothhammer-Hampl T, Zoubaa S, Riemenschneider MJ. Writing, review and/or revision of the manuscript: Lorenz J, Riemenschneider MJ, Zoubaa S, Bumes E, Pukrop T, Kölbl O, Corbacioglu S, Schmidt NO, Proescholdt M, Hau P. Administrative, technical, or material support: Proescholdt M, Schmidt NO, Bumes E, Hau P. Study supervision: Riemenschneider MJ. The author(s) read and approved the final manuscript.

\section{Funding}

Open access funding provided by Projekt DEAL.

\section{Availability of data and materials}

All data generated or analyzed during this study are included in this published article (and its supplementary information files). Raw data are available from the corresponding author on reasonable request.

\section{Ethics approval and consent to participate}

The Institutional Review Board approval (reference number: 19-1465-101) and informed consent forms are on file at the Brain Tumor Center and Wilhelm Sander Neuro-Oncology Unit, Regensburg, Germany.

\section{Competing interests}

The authors declare they have no competing interests.

\section{Author details}

'Department of Neuropathology, Regensburg University Hospital, Franz-Josef-Strauss-Allee 11, 93053 Regensburg, Germany. ${ }^{2}$ Wilhelm Sander Neuro-Oncology Unit, Regensburg University Hospital, Regensburg, Germany.
${ }^{3}$ Department of Neurology, Regensburg University Hospital, Regensburg, Germany. ${ }^{4}$ Department of Internal Medicine III, Regensburg University Hospital, Regensburg, Germany. ${ }^{5}$ Department of Radiotherapy, Regensburg University Hospital, Regensburg, Germany. ${ }^{6}$ Department of Pediatric Hematology, Oncology and Stem Cell Transplantation, Regensburg University Hospital, Regensburg, Germany. ${ }^{7}$ Department of Neurosurgery, University Hospital Regensburg, Regensburg, Germany.

Received: 19 May 2020 Accepted: 17 July 2020

Published online: 05 August 2020

\section{References}

1. Louis ND, Ohgaki H, Wiestler OD, Cavenee WK, Ellison DW, Figarella-Branger D, Perry A, Reifenberger G, von Deimling A (2016) WHO classification of tumors of the central nervous system, revised 4th edition. International Agency for Research on Cancer (IARC), Lyon

2. Brat DJ, Aldape K, Colman H, Holland EC, Louis DN, Jenkins RB, Kleinschmidt-DeMasters BK, Perry A, Reifenberger G, Stupp R, von Deimling A, Weller M (2018) CIMPACT-NOW update 3: recommended diagnostic criteria for "diffuse astrocytic glioma, IDH-wildtype, with molecular features of glioblastoma, WHO grade IV". Acta Neuropathol 136(5):805-810. https://doi.org/10.1007/s00401-018-1913-0

3. Shirahata M, Ono T, Stichel D, Schrimpf D, Reuss DE, Sahm F, Koelsche C, Wefers A, Reinhardt A, Huang K, Sievers P, Shimizu H, Nanjo H, Kobayashi Y, Miyake Y, Suzuki T, Adachi J-I, Mishima K, Sasaki A, Nishikawa R, BewerungeHudler M, Ryzhova M, Absalyamova O, Golanov A, Sinn P, Platten M, Jungk C, Winkler F, Wick A, Hänggi D et al (2018) Novel, improved grading system(s) for IDH-mutant astrocytic gliomas. Acta Neuropathol 136(1):153166. https://doi.org/10.1007/s00401-018-1849-4

4. Domingues PH, Sousa P, Otero Á, Gonçalves JM, Ruiz L, de Oliveira C, Lopes MC, Orfao A, Tabernero MD (2014) Proposal for a new risk stratification classification for meningioma based on patient age, WHO tumor grade, size, localization, and karyotype. Neuro Oncol 16(5):735-747. https://doi.org/10. 1093/neuonc/not325

5. Suppiah S, Nassiri F, Bi WL, Dunn IF, Hanemann CO, Horbinski CM, Hashizume R, James CD, Mawrin C, Noushmehr H, Perry A, Sahm F, Sloan A, von Deimling A, Wen PY, Aldape K, Zadeh G (2019) Molecular and translational advances in meningiomas. Neuro Oncology 21(Suppl 1):i4-i17. https://doi.org/10.1093/neuonc/noy178

6. Sahm F, Schrimpf D, Stichel D, Jones DTW, Hielscher T, Schefzyk S, Okonechnikov K, Koelsche C, Reuss DE, Capper D, Sturm D, Wirsching H-G, Berghoff AS, Baumgarten P, Kratz A, Huang K, Wefers AK, Hovestadt V, Sill M, Ellis HP, Kurian KM, Okuducu AF, Jungk C, Drueschler K, Schick M, Bewerunge-Hudler M, Mawrin C, Seiz-Rosenhagen M, Ketter R, Simon M et al (2017) DNA methylation-based classification and grading system for meningioma: a multicentre, retrospective analysis. Lancet Oncol 18(5):682694. https://doi.org/10.1016/S1470-2045(17)30155-9

7. Reuss DE, Piro RM, Jones DTW, Simon M, Ketter R, Kool M, Becker A, Sahm F, Pusch S, Meyer J, Hagenlocher C, Schweizer L, Capper D, Kickingereder P, Mucha J, Koelsche C, Jäger N, Santarius T, Tarpey PS, Stephens PJ, Andrew Futreal P, Wellenreuther R, Kraus J, Lenartz D, Herold-Mende C, Hartmann C, Mawrin C, Giese N, Eils R, Collins VP et al (2013) Secretory meningiomas are defined by combined KLF4 K409Q and TRAF7 mutations. Acta Neuropathol 125(3):351-358. https://doi.org/10.1007/s00401-013-1093-x

8. Taylor MD, Northcott PA, Korshunov A, Remke M, Cho Y-J, Clifford SC, Eberhart CG, Parsons DW, Rutkowski S, Gajjar A, Ellison DW, Lichter P, Gilbertson RJ, Pomeroy SL, Kool M, Pfister SM (2012) Molecular subgroups of medulloblastoma: the current consensus. Acta Neuropathol 123(4):465-472. https://doi.org/10.1007/s00401-011-0922-z

9. Pugh TJ, Weeraratne SD, Archer TC, Pomeranz Krummel DA, Auclair D, Bochicchio J, Carneiro MO, Carter SL, Cibulskis K, Erlich RL, Greulich H, Lawrence MS, Lennon NJ, McKenna A, Meldrim J, Ramos AH, Ross MG, Russ C, Shefler E, Sivachenko A, Sogoloff B, Stojanov P, Tamayo P, Mesirov JP, Amani V, Teider N, Sengupta S, Francois JP, Northcott PA, Taylor MD et al (2012) Medulloblastoma exome sequencing uncovers subtype-specific somatic mutations. Nature 488(7409):106-110. https://doi.org/10.1038/ nature 11329

10. Pietsch T, Haberler C (2016) Update on the integrated histopathological and genetic classification of medulloblastoma - a practical diagnostic guideline. Clin Neuropathol 35(6):344-352. https://doi.org/10.5414/NP300999 
11. Sturm D, Witt H, Hovestadt V, Khuong-Quang D-A, Jones DTW, Konermann C, Pfaff E, Tönjes M, Sill M, Bender S, Kool M, Zapatka M, Becker N, Zucknick M, Hielscher T, Liu X-Y, Fontebasso AM, Ryzhova M, Albrecht S, Jacob K, Wolter M, Ebinger M, Schuhmann MU, van Meter T, Frühwald MC, Hauch $H$, Pekrun A, Radlwimmer B, Niehues T, von Komorowski G et al (2012) Hotspot mutations in $\mathrm{H} 3 \mathrm{~F} 3 \mathrm{~A}$ and IDH1 define distinct epigenetic and biological subgroups of glioblastoma. Cancer Cell 22(4):425-437. https://doi.org/10. 1016/j.ccr.2012.08.024

12. Northcott PA, Buchhalter I, Morrissy AS, Hovestadt V, Weischenfeldt J, Ehrenberger T, Gröbner S, Segura-Wang M, Zichner T, Rudneva VA, Warnatz H-J, Sidiropoulos N, Phillips AH, Schumacher S, Kleinheinz K, Waszak SM, Erkek S, Jones DTW, Worst BC, Kool M, Zapatka M, Jäger N, Chavez L, Hutter B, Bieg M, Paramasivam N, Heinold M, Gu Z, Ishaque N, Jäger-Schmidt C et al (2017) The whole-genome landscape of medulloblastoma subtypes. Nature 547(7663):311-317. https://doi.org/10.1038/nature22973

13. Sahm F, Schrimpf D, Jones DTW, Meyer J, Kratz A, Reuss D, Capper D, Koelsche C, Korshunov A, Wiestler B, Buchhalter I, Milde T, Selt F, Sturm D, Kool M, Hummel M, Bewerunge-Hudler M, Mawrin C, Schüller U, Jungk C, Wick A, Witt O, Platten M, Herold-Mende C, Unterberg A, Pfister SM, Wick W, von Deimling A (2016) Next-generation sequencing in routine brain tumor diagnostics enables an integrated diagnosis and identifies actionable targets. Acta Neuropathol 131(6):903-910. https://doi.org/10.1007/s00401015-1519-8

14. Griffith M, Spies NC, Krysiak K, McMichael JF, Coffman AC, Danos AM, Ainscough BJ, Ramirez CA, Rieke DT, Kujan L, Barnell EK, Wagner AH, Skidmore ZL, Wollam A, Liu CJ, Jones MR, Bilski RL, Lesurf R, Feng Y-Y, Shah NM, Bonakdar M, Trani L, Matlock M, Ramu A, Campbell KM, Spies GC, Graubert AP, Gangavarapu K, Eldred JM, Larson DE et al (2017) CIViC is a community knowledgebase for expert crowdsourcing the clinical interpretation of variants in cancer. Nat Genet 49(2):170-174. https://doi.org/ 10.1038/ng.3774

15. Zhang J, Baran J, Cros A, Guberman JM, Haider S, Hsu J, Liang Y, Rivkin E, Wang J, Whitty B, Wong-Erasmus M, Yao L, Kasprzyk A (2011) International Cancer genome consortium data portal--a one-stop shop for cancer genomics data. Database (Oxford) 2011:bar026. https://doi.org/10.1093/ database/bar026

16. Illumina, Inc. (2014) bcl2fastq Conversion Software v1.8.4 User Guide. https://emea.support.illumina.com/content/dam/illuminasupport/ documents/documentation/software_documentation/bcl2fastq/bcl2fastq_ letterbooklet_15038058brpmi.pdf

17. Martin M (2011) Cutadapt removes adapter sequences from highthroughput sequencing reads. EMBnet J 17(1):10. https://doi.org/10.14806/ ej.17.1.200

18. Andrews S (2010) FASTQC. A quality control tool for high throughput sequence data. BibSonomy. https://www.bibsonomy.org/bibtex/f230a91 9c34360709aa298734d63dca3\#export

19. Li, H (2013) Aligning sequence reads, clone sequences and assembly contigs with BWA-MEM. ArXiv:1303.3997. https://arxiv.org/abs/1303.3997

20. Li H, Handsaker B, Wysoker A, Fennell T, Ruan J, Homer N, Marth G, Abecasis G, Durbin R (2009) The sequence alignment/map format and SAMtools. Bioinformatics 25(16):2078-2079. https://doi.org/10.1093/bioinformatics/ btp352

21. Agilent Genomics NextGen Toolkit: Locatlt. Agilent. https://www.agilent. com/en/product/next-generation-sequencing/hybridization-based-nextgeneration-sequencing-ngs/ngs-software/agent-232879. Accessed 21 Oct 2014

22. Koboldt DC, Zhang Q, Larson DE, Shen D, McLellan MD, Lin L, Miller CA, Mardis ER, Ding L, Wilson RK (2012) VarScan 2: somatic mutation and copy number alteration discovery in cancer by exome sequencing. Genome Res 22(3):568-576. https://doi.org/10.1101/gr.129684.111

23. Wang K, Li M, Hakonarson H (2010) ANNOVAR: functional annotation of genetic variants from high-throughput sequencing data. Nucleic Acids Res 38(16):e164. https://doi.org/10.1093/nar/gkq603

24. Robinson JT, Thorvaldsdóttir H, Winckler W, Guttman M, Lander ES, Getz G, Mesirov JP (2011) Integrative genomics viewer. Nature Biotechnology 29: 24-26. https://doi.org/10.1038/nbt.1754

25. Werness BA, Parvatiyar P, Ramus SJ, Whittemore AS, Garlinghouse-Jones K, Oakley-Girvan I, DiCioccio RA, Wiest J, Tsukada Y, Ponder BA, Piver MS (2000) Ovarian carcinoma in situ with germline BRCA1 mutation and loss of heterozygosity at BRCA1 and TP53. J Natl Cancer Inst 92(13):1088-1091. https://doi.org/10.1093/jnci/92.13.1088
26. Seshan EV, Olshen BA (2010) DNAcopy: A Package for Analyzing DNA Copy Data. Bioconductor. https://bioconductor.org/packages/release/bioc/html/ DNAcopy.html

27. Gu Z, Eils R, Schlesner M (2016) Complex heatmaps reveal patterns and correlations in multidimensional genomic data. Bioinformatics 32(18):28472849. https://doi.org/10.1093/bioinformatics/btw313

28. Dietmaier W, Lorenz J, Riemenschneider MJ (2015) Molekulare Diagnostik in der Neuropathologie. Pathologe 36(2):171-180. https://doi.org/10.1007/ s00292-015-0002-6

29. Nonoguchi N, Ohta T, Oh J-E, Kim Y-H, Kleihues P, Ohgaki H (2013) TERT promoter mutations in primary and secondary glioblastomas. Acta Neuropathol 126(6):931-937. https://doi.org/10.1007/s00401-013-1163-0

30. Bieńkowski M, Piaskowski S, Stoczyńska-Fidelus E, Szybka M, Banaszczyk M, Witusik-Perkowska M, Jesień-Lewandowicz E, Jaskólski DJ, Radomiak-Załuska A, Jesionek-Kupnicka D, Sikorska B, Papierz W, Rieske P, Liberski PP (2013) Screening for EGFR amplifications with a novel method and their significance for the outcome of glioblastoma patients. PLoS One 8(6): e65444. https://doi.org/10.1371/journal.pone.0065444

31. Sciacchitano S, Lavra L, Ulivieri A, Magi F, de Francesco GP, Bellotti C, Salehi LB, Trovato M, Drago C, Bartolazzi A (2017) Comparative analysis of diagnostic performance, feasibility and cost of different test-methods for thyroid nodules with indeterminate cytology. Oncotarget 8(30):4942149442. https://doi.org/10.18632/oncotarget.17220

32. ILAC inspection committee (2019) Guidance on measurements performed as part of an inspection process. https://ilac.org/?ddownload=122667

33. DAkks Deutsche Akkreditierungsstelle (2012) Checkliste zur DIN EN ISO/IEC 17020:2012 für die Molekularpathologie. https://www.dakks.de/content/ checkliste-zur-din-en-isoiec-170202012-für-die-molekularpathologie

34. Schindler G, Capper D, Meyer J, Janzarik W, Omran H, Herold-Mende C, Schmieder K, Wesseling P, Mawrin C, Hasselblatt M, Louis DN, Korshunov A, Pfister S, Hartmann C, Paulus W, Reifenberger G, von Deimling A (2011) Analysis of BRAF V600E mutation in 1,320 nervous system tumors reveals high mutation frequencies in pleomorphic xanthoastrocytoma, ganglioglioma and extra-cerebellar pilocytic astrocytoma. Acta Neuropathol 121(3):397-405. https://doi.org/10.1007/s00401-011-0802-6

35. Razis E, Kotoula V, Koliou G-A, Papadopoulou K, Vrettou E, Giannoulatou E, Tikas I, Labropoulos SV, Rigakos G, Papaemmanoyil S, Romanidou O, Bourkoula E, Nomikos P, Iliadis G, Nasioulas G, Selviaridis P, Polyzoidis K, Fountzilas G (2019) Is there an independent role of TERT and NF1 in high grade Gliomas? Transl Oncol 13(2):346-354. https://doi.org/10.1016/j.tranon.2019.10.016

36. Appin CL, Brat DJ (2014) Molecular genetics of gliomas. Cancer J 20(1):6672. https://doi.org/10.1097/PPO.0000000000000020

37. Ruttledge $M H$, Sarrazin J, Rangaratnam S, Phelan CM, Twist E, Merel $P$, Delattre O, Thomas G, Nordenskjöld M, Collins VP (1994) Evidence for the complete inactivation of the NF2 gene in the majority of sporadic meningiomas. Nat Genet 6(2):180-184. https://doi.org/10.1038/ng0294-180

38. Remke M, Ramaswamy V, Peacock J, Shih DJH, Koelsche C, Northcott PA, Hill N, Cavalli FMG, Kool M, Wang X, Mack SC, Barszczyk M, Morrissy AS, Wu X, Agnihotri S, Luu B, Jones DTW, Garzia L, Dubuc AM, Zhukova N, Vanner R, Kros JM, French PJ, van Meir EG, Vibhakar R, Zitterbart K, Chan JA, Bognár L, Klekner A, Lach B et al (2013) TERT promoter mutations are highly recurrent in SHH subgroup medulloblastoma. Acta Neuropathol 126(6):917-929. https://doi.org/10.1007/s00401-013-1198-2

39. Cavalli FMG, Remke M, Rampasek L, Peacock J, Shih DJH, Luu B, Garzia L, Torchia J, Nor C, Morrissy AS, Agnihotri S, Thompson YY, Kuzan-Fischer CM, Farooq H, Isaev K, Daniels C, Cho B-K, Kim S-K, Wang K-C, Lee JY, Grajkowska WA, Perek-Polnik M, Vasiljevic A, Faure-Conter C, Jouvet A, Giannini C, Nageswara Rao AA, Li KKW, Ng H-K, Eberhart CG et al (2017) Intertumoral heterogeneity within Medulloblastoma Subgroups. Cancer Cell 31(6):737754.e6. https://doi.org/10.1016/j.ccell.2017.05.005

40. Wen PY, Norden AD, Drappatz J, Quant E (2010) Response assessment challenges in clinical trials of gliomas. Curr Oncol Rep 12(1):68-75. https://doi.org/10.1007/s11912-009-0078-3

41. Nikiforova MN, Wald Al, Melan MA, Roy S, Zhong S, Hamilton RL, Lieberman FS, Drappatz J, Amankulor NM, Pollack IF, Nikiforov YE, Horbinski C (2016) Targeted next-generation sequencing panel (GlioSeq) provides comprehensive genetic profiling of central nervous system tumors. Neuro Oncology 18(3):379-387. https://doi.org/10.1093/neuonc/nov289

42. McNulty SN, Cottrell CE, Vigh-Conrad KA, Carter JH, Heusel JW, Ansstas G, Dahiya S (2019) Beyond sequence variation: assessment of copy number 
variation in adult glioblastoma through targeted tumor somatic profiling. Hum Pathol 86:170-181. https://doi.org/10.1016/.humpath.2018.12.004

43. Carter JH, MCNulty SN, Cimino PJ, Cottrell CE, Heusel JW, Vigh-Conrad KA, Duncavage EJ (2017) Targeted next-generation sequencing in molecular subtyping of lower-grade diffuse Gliomas: application of the World Health Organization's 2016 revised criteria for central nervous system tumors. J Mol Diagn 19(2):328-337. https://doi.org/10.1016/j.jmoldx.2016.10.010

44. Synhaeve NE, van den Bent MJ, French PJ, Dinjens WNM, Atmodimedjo PN, Kros JM, Verdijk R, Dirven CMF, Dubbink HJ (2018) Clinical evaluation of a dedicated next generation sequencing panel for routine glioma diagnostics. Acta Neuropathol Commun:6. https://doi.org/10.1186/s40478-018-0633-y

45. Zacher A, Kaulich K, Stepanow S, Wolter M, Köhrer K, Felsberg J, Malzkorn B, Reifenberger G (2017) Molecular diagnostics of Gliomas using next generation sequencing of a Glioma-tailored gene panel. Brain Pathol 27(2): 146-159. https://doi.org/10.1111/bpa.12367

46. Ji MS, Eldred BSC, Liu R, Pianka ST, Molaie D, Kevan B, Pan S, Lai TJ, Nguyen NT, Chow FE, Yong WH, Cox CD, Reeh DN, Li T, Liau LM, Nghiemphu PL, Cloughesy TF, Li G, Lai A (2020) Targeted next-generation sequencing of 565 neuro-oncology patients at UCLA: a single-institution experience. Neurooncol Adv 2(1):vdaa009. https://doi.org/10.1093/noajn//vdaa009

47. Jones DTW, Kocialkowski S, Liu L, Pearson DM, Bäcklund LM, Ichimura K, Collins VP (2008) Tandem duplication producing a novel oncogenic BRAF fusion gene defines the majority of pilocytic astrocytomas. Cancer Res 68(21):8673-8677. https://doi.org/10.1158/0008-5472.CAN-08-2097

48. Parker M, Mohankumar KM, Punchihewa C, Weinlich R, Dalton JD, Li Y, Lee R, Tatevossian RG, Phoenix TN, Thiruvenkatam R, White E, Tang B, Orisme W, Gupta K, Rusch M, Chen X, Li Y, Nagahawhatte P, Hedlund E, Finkelstein D, Wu G, Shurtleff S, Easton J, Boggs K, Yergeau D, Vadodaria B, Mulder HL, Becksfort J, Becksford J, Gupta P et al (2014) C11 orf95-RELA fusions drive oncogenic NF-KB signalling in ependymoma. Nature 506(7489):451-455. https://doi.org/10.1038/nature13109

49. Sturm D, Orr BA, Toprak UH, Hovestadt V, Jones DTW, Capper D, Sill M, Buchhalter I, Northcott PA, Leis I, Ryzhova M, Koelsche C, Pfaff E, Allen SJ, Balasubramanian G, Worst BC, Pajtler KW, Brabetz S, Johann PD, Sahm F, Reimand J, Mackay A, Carvalho DM, Remke M, Phillips JJ, Perry A, Cowdrey C, Drissi R, Fouladi M, Giangaspero F et al (2016) New brain tumor entities emerge from molecular classification of CNS-PNETs. Cell 164(5):1060-1072 https://doi.org/10.1016/j.cell.2016.01.015

50. Singh D, Chan JM, Zoppoli P, Niola F, Sullivan R, Castano A, Liu EM, Reichel J, Porrati P, Pellegatta S, Qiu K, Gao Z, Ceccarelli M, Riccardi R, Brat DJ, Guha A, Aldape K, Golfinos JG, Zagzag D, Mikkelsen T, Finocchiaro G, Lasorella A, Rabadan R, lavarone A (2012) Transforming fusions of FGFR and TACC genes in human glioblastoma. Science 337(6099):1231-1235. https://doi.org/ 10.1126/science.1220834

51. Wu G, Diaz AK, Paugh BS, Rankin SL, Ju B, Li Y, Zhu X, Qu C, Chen X, Zhang J, Easton J, Edmonson M, Ma X, Lu C, Nagahawatte P, Hedlund E, Rusch M, Pounds S, Lin T, Onar-Thomas A, Huether R, Kriwacki R, Parker M, Gupta P, Becksfort J, Wei L, Mulder HL, Boggs K, Vadodaria B, Yergeau D et al (2014) The genomic landscape of diffuse intrinsic pontine glioma and pediatric non-brainstem high-grade glioma. Nat Genet 46(5):444-450. https://doi.org/ 10.1038/ng.2938

52. Zhang J, Wu G, Miller CP, Tatevossian RG, Dalton JD, Tang B, Orisme W, Punchihewa C, Parker M, Qaddoumi I, Boop FA, Lu C, Kandoth C, Ding L, Lee R, Huether R, Chen X, Hedlund E, Nagahawatte P, Rusch M, Boggs K, Cheng J, Becksfort J, Ma J, Song G, Li Y, Wei L, Wang J, Shurtleff S, Easton J. et al (2013) Whole-genome sequencing identifies genetic alterations in pediatric low-grade gliomas. Nat Genet 45(6):602-612. https://doi.org/10. 1038/ng.2611

\section{Publisher's Note}

Springer Nature remains neutral with regard to jurisdictional claims in published maps and institutional affiliations.

Ready to submit your research? Choose BMC and benefit from:

- fast, convenient online submission

- thorough peer review by experienced researchers in your field

- rapid publication on acceptance

- support for research data, including large and complex data types

- gold Open Access which fosters wider collaboration and increased citations

- maximum visibility for your research: over $100 \mathrm{M}$ website views per year

At BMC, research is always in progress.

Learn more biomedcentral.com/submissions 